\title{
Resistance to Phytophthora cactorum in Diploid Fragaria Species
}

\author{
Hävard Eikemo and May B. Brurberg \\ Norwegian Institute for Agricultural and Environmental Research, Plant \\ Health and Plant Protection Division, Høgskoleveien 7, N-1432 As, Norway
}

\author{
Jahn Davik ${ }^{1}$ \\ Norwegian Institute for Agricultural and Environmental Research, Genetics \\ and Biotechnology, Kvithamar, Stjørdal, Norway 7500
}

Additional index words. Fragaria ssp., Phytophthora cactorum, disease resistance, greenhouse screen, genetic variance

\begin{abstract}
Sixty accessions/genotypes (entries) of diploid Fragaria sp. were tested for susceptibility to Phytophthora cactorum in greenhouse tests. Four experiments, each with four to 35 entries, were conducted, and each entry was represented by 36 to 45 plants per experiment. The plants were graded according to the number of weeks of survival during the first 4 weeks and for plants surviving more than the first 4 weeks, scoring was based on amount of necrosis in the crown. Statistical analysis showed no significant difference among the four experiments. A majority of the accessions (48) were categorized as being resistant or moderately resistant to Phytophthora cactorum. The disease score for this group varied from 1.06 to 3.09. Five accessions with disease scores ranging from 6.25 to 7.43 were considered highly susceptible. Within $F$. vesca, a highly significant proportion of the total variation in disease scores $(57.6 \%)$ was attributable to the differences between accessions and, hence, of genetic nature. There was no indication of any Fragaria species being more resistant or susceptible than others and no systematic differences resulting from geographic origin.
\end{abstract}

The genus Fragaria in the rose family (Rosaceae) is well known for their edible fruits, and the economically important octoploid Fragaria $\times$ ananassa Dutch. produces large red strawberries and is grown all over the world. In 2007, the world production of strawberries was more than 3.8 million $t$ (FAOStat Agricultural Data, http://www.fao.org). However, annually, strawberry producers face serious economical losses as a result of the development of diseases caused by pathogens, one of them being the destructive oomycete Phytophthora cactorum (Lebert \& Cohn) J. Schröt., which causes crown rot.

$P$. cactorum causes disease in more than 200 plant species, including 150 genera representing 60 plant families, several of them within the rose family (Erwin and Ribeiro, 1996). The pathogen causes fruit rot, root and crown rot, cankers, leaf blights, wilt, and seedling blight (Nienhaus, 1960). $P$. cactorum was first reported as the cause of crown rot of strawberry ( $F$. Xananassa

Received for publication 14 Oct. 2009. Accepted for publication 29 Nov. 2009.

This work was supported by grant 179476/I30 from the Research Council of Norway.

We thank the National Clonal Germplasm Repository (Corvallis, OR), East Malling Research (U.K.), and Anita Sønsteby for providing accessions included in this study. We are grateful to Monica Skogen, Grete Lund, Andrew Dobson, Anne Langerud, and Randi Wikdahl for technical assistance.

${ }^{1}$ To whom reprint requests should be addressed; e-mail jahn.davik@bioforsk.no.
Dutch.) in 1952 in Germany (Deutschmann, 1954). It has since become an important disease in most European countries and can be a limiting factor to successful strawberry production worldwide (Maas, 1998).

$P$. cactorum is homothallic and produces oospores in diseased plant tissue, which makes the pathogen able to survive in the soil for many years. There are few means of eradicating it once a field has become infested, and even with fumigation, this pathogen is rarely eliminated (Sneh and McIntosh, 1974; Wilhelm and Paulus, 1980). It is therefore also almost impossible to eliminate all sources of infection in strawberry nurseries (Fennimore et al., 2008). Many of the most commonly grown strawberry cultivars in Europe are susceptible to $P$. cactorum (Eikemo et al., 2003) and this enhances the spreading of the disease and the severity of the disease outbreaks. However, genotypes resistant to crown rot do exist. These include accessions from the octoploid species $\mathrm{Fra}$ garia chiloensis and Fragaria virginiana, species that have been used as sources for other useful traits in strawberry breeding (Hancock et al., 2002).

van de Weg (1997) postulated one single dominant major gene for the resistance to the oomycete Phytophthora fragaria var. fragaria in strawberry. For resistance to Phytophthora root rot caused by Phytophthora fragaria var. rubi in the closely related diploid red raspberry (Rubus ideaus), a two-gene model with dominance has been suggested (Pattison et al., 2007). Previous findings do not support a simple model for $P$. cactorum resistance in $F$. ×ananassa. Shaw et al. (2006, 2008) indicated an additive, polygenically inherited resistance, and Denoyes-Rothan et al. (2004) found five putative quantitative trait loci for resistance in an experimental $F$. Xananassa population. Focusing on a simpler system than the octoploid strawberry, e.g., a diploid model system, thus appears attractive to get an understanding of the nature and inheritance of the Phytophthora crown rot resistance.

$F$. vesca has several features that make it attractive as a model species. The plants are easily grown and propagated both through seeds and runners, and they are relatively easy to transform genetically (Oosumi et al., 2006). Moreover, the $F$. vesca genome is only slightly larger than the genome of Arabidosis thaliana (Folta and Davis, 2006), and genetic maps exist for both the diploid (Cipriani et al., 2006; Davis and Yu, 1997; Sargent et al., 2004, 2006) and the octoploid strawberry (Lerceteau-Köhler et al., 2003; Weebadde et al., 2008). Finally, a high degree of macrosynteny and colinearity between diploid and octoploid strawberry exist, and no major chromosomal rearrangements seem to have occurred (Rousseau-Gueutin et al., 2008).

The octoploid strawberry progenitors $F$. virginiana and $F$. chiloensis are believed to be diploidized allopolyploids, each descending from four diploid ancestors. The ancestry of $F$. virginiana and $F$. chiloensis is not fully known, but the main diploid candidates are $F$. vesca, $F$. iinumae, $F$. nubicola, and $F$. orientalis (Folta and Davis, 2006; Potter et al., 2000). This conserved organization within the Fragaria genus supports the use of diploid Fragaria as a model system for gaining genetic knowledge that subsequently can be transferred to the more complex and economically important octoploid $F$. ×ananassa (Davis and Yu, 1997; Sargent et al., 2004).

The work presented here is part of a project in which the main goal is to generate basic knowledge about $P$. cactorum resistance in diploid strawberry species. Second, we aim to identify genes and develop genetic markers that can be used as tools in the amelioration of resistant strawberry cultivars or to develop more effective control measures for disease management. Gaining knowledge about the general level of resistance/susceptibility in our model species is a natural first step and the screening of selected genotypes of diverse geographic origin is reported here.

\section{Materials and Methods}

Plant material and plant propagation. Accessions of wild strawberry were either collected as runners across Norway or obtained as seeds from East Malling Research (Kent, U.K.) or the National Clonal Germplasm Repository (Corvallis, OR). The accessions come from all over the world with 36 originating from Europe, 14 from Asia, eight from the Americas, and one accession being of unknown origin (Table 1). 


\begin{tabular}{|c|c|c|c|c|c|c|c|c|}
\hline \multirow[b]{2}{*}{ Accession $^{z}$} & \multirow{2}{*}{$\begin{array}{l}\text { Accession } \\
\text { received as }\end{array}$} & \multirow[b]{2}{*}{ Species/subspecies } & \multirow[b]{2}{*}{ Country of origin } & \multicolumn{4}{|c|}{ Disease scores } & \multirow{2}{*}{$\begin{array}{c}\text { Least square } \\
\text { means disease } \\
\text { scores and the } \\
\text { corresponding SES }\end{array}$} \\
\hline & & & & Expt. 1 & Expt. 2 & Expt. 3 & $\overline{\text { Expt. } 4}$ & \\
\hline$\overline{\text { CFRA1363 }}$ & Seed & vesca & Bolivia & & 1.07 & 1.07 & & $1.06 \pm 0.64$ \\
\hline CFRA1603 & Seed & vesca/vesca & Bulgaria & & 1.07 & 1.27 & & $1.16 \pm 0.64$ \\
\hline CFRA573 & Seed & vesca/vesca & NA & & 1.20 & & & $1.22 \pm 0.92$ \\
\hline CFRA564 & Seed & vesca/vesca & Russia & & 1.27 & 1.27 & & $1.26 \pm 0.64$ \\
\hline CFRA1024 & Seed & vesca & Sweden & & 1.27 & & & $1.29 \pm 0.92$ \\
\hline CFRA1825 & Seed & nilgerrensis & China (Yunnan) & & 1.33 & 1.33 & & $1.33 \pm 0.64$ \\
\hline Ås 2 & Runners & vesca & Norway & 1.53 & 1.20 & & & $1.38 \pm 0.65$ \\
\hline CFRA980 & Seed & vesca & Kazakhstan & & 1.27 & 1.53 & & $1.39 \pm 0.64$ \\
\hline CFRA197 & Seed & vesca & Hawaii $^{y}$ & 1.27 & & & 1.53 & $1.41 \pm 0.64$ \\
\hline CFRA1025 & Seed & vesca & Sweden & & 1.20 & 1.67 & & $1.43 \pm 0.64$ \\
\hline KOPPAREN & Runners & vesca & Norway & 1.53 & & & & $1.55 \pm 0.92$ \\
\hline CFRA1309 & Seed & vesca & Italy & & 1.53 & & & $1.56 \pm 0.92$ \\
\hline CFRA1610 & Seed & nilgerrensis & China (Hubei) & & 1.53 & & & $1.56 \pm 0.92$ \\
\hline Haugastøl 2 & Runners & vesca & Norway & 1.53 & & 1.60 & & $1.56 \pm 0.65$ \\
\hline CFRA1364 & Seed & vesca & Italy & & 1.60 & & & $1.62 \pm 0.92$ \\
\hline ALTA & Runners & vesca & Norway & 1.60 & 1.67 & & & $1.65 \pm 0.65$ \\
\hline Ås 3 & Runners & vesca & Norway & 1.67 & & & & $1.68 \pm 0.92$ \\
\hline FDP405 & Seed & nilgerrensis & China (Guizhou) & 1.80 & 1.53 & & & $1.68 \pm 0.65$ \\
\hline RÅDAL & Runners & vesca & Norway & 1.67 & & & & $1.68 \pm 0.92$ \\
\hline GRYTØY & Runners & vesca & Norway & 1.73 & & & & $1.75 \pm 0.92$ \\
\hline GRYTØY 3 & Runners & vesca & Norway & 1.80 & & & & $1.81 \pm 0.92$ \\
\hline NAMSOS & Runners & vesca & Norway & 1.87 & & & & $1.88 \pm 0.92$ \\
\hline CFRA1861 & Seed & nipponica & Japan & & 1.93 & & & $1.95 \pm 0.92$ \\
\hline CFRA1001 & Seed & vesca & Ecuador & & 1.93 & & & $1.96 \pm 0.92$ \\
\hline NAMSOS 2 & Runners & vesca & Norway & 3.07 & & 2.47 & & $2.76 \pm 0.65$ \\
\hline HARDANGER 3 & Runners & vesca & Norway & 3.60 & & 2.13 & & $2.86 \pm 0.65$ \\
\hline CFRA1855 & Seed & iinumae & Japan & & 2.93 & & & $2.95 \pm 0.92$ \\
\hline Ljøen & Runners & vesca & Norway & 3.70 & & 2.27 & & $2.96 \pm 0.65$ \\
\hline CFRA 1850 & Seed & iinumae & Japan & & 3.07 & & & $3.09 \pm 0.92$ \\
\hline CFRA1856 & Seed & iinumae & Japan & & 3.07 & & & $3.09 \pm 0.92$ \\
\hline CFRA1866 & Seed & nipponica & Japan & & 3.47 & & & $3.49 \pm 0.92$ \\
\hline CFRA479 & Seed & vesca/vesca & Germany & 3.54 & & & & $3.56 \pm 0.92$ \\
\hline FDP818 & Seed & vesca/californica & USA (California) & 3.87 & & & & $3.94 \pm 0.92$ \\
\hline CFRA565 & Seed & vesca/vesca & Russia & & 4.00 & & & $4.02 \pm 0.92$ \\
\hline CFRA1869 & Seed & nipponica & Japan & & 3.67 & 5.00 & & $4.33 \pm 0.64$ \\
\hline CFRA1428 & Seed & vesca & Bolivia & & 5.80 & 3.07 & & $4.43 \pm 0.62$ \\
\hline FDP 815 (I3) & Seed & vesca/vesca & Germany & 2.60 & 5.13 & 7.73 & & $5.15 \pm 0.52$ \\
\hline CFRA175 & Seed & vesca/crinita & USA (Oregon) & & 5.80 & 6.73 & & $6.25 \pm 0.64$ \\
\hline Haugastøl 3 & Runners & vesca & Norway & 5.80 & & 7.53 & & $6.65 \pm 0.65$ \\
\hline CFRA1218 & Seed & vesca & Europe $^{\mathrm{x}}$ & & 6.07 & 8.00 & & $7.02 \pm 0.64$ \\
\hline FDP821 & Seed & vesca/americana & USA (South Dakota) & 7.00 & 7.40 & 7.73 & 7.20 & $7.33 \pm 0.44$ \\
\hline CFRA424 & Seed & vesca/bracteata & USA (Oregon) & & 6.87 & 8.00 & & $7.43 \pm 0.64$ \\
\hline
\end{tabular}

${ }^{\mathrm{z}}$ All accessions with the CFRA prefix were obtained from the National Clonal Germplasm Repository, Corvallis, OR. Accessions with the FDP prefix were obtained from East Malling Research, East Malling, U.K.

${ }^{\mathrm{y}}$ This accession is believed not to be indigenous to Hawaii.

${ }^{x}$ European country unknown.

$\mathrm{NA}=$ not available

The 60 accessions of diploid Fragaria sp. belong to the species $F$. vesca (48, including different subspecies), $F$. nilgerensis (three), $F$. iinumae (three), F. nipponica (three), $F$. bucharica (one), F. nubicola (one), and $F$. pentaphylla (one). Seed was germinated in mist chambers. All accessions were propagated as runner plants for use in the resistance test experiments. One representative plant, originating from either seed or runners, was used as a source for all the runner plants. Propagation was done in a greenhouse with
$16 \mathrm{~h}$ day $/ 20{ }^{\circ} \mathrm{C}$ and $8 \mathrm{~h}$ night $/ 14{ }^{\circ} \mathrm{C}$. After multiplication and establishment, the plants were grown for an additional 1 to 2 weeks before pathogen inoculation. Artificial light was provided by high-pressure sodium lamps (SON/T, $120 \mu E \cdot \mathrm{s}^{-1} \cdot \mathrm{m}^{-2}$ ) in periods with less 
than $16 \mathrm{~h}$ of natural light. Before inoculation, the plants were subjectively graded for size relative to each other using a 1 to 3 scale.

Preparation of inoculum, inoculation, and disease scoring. One isolate (Bioforsk isolate ID number 10300) of P. cactorum, originally isolated from the rhizome of a field-grown strawberry plant in Norway, was used in all experiments. Previous tests of aggressiveness revealed no differences between P. cactorum isolates (Eikemo, 1998). In agreement with this, amplified fragment length polymorphism displayed a very low level of molecular variation within the crown rot pathotype of $P$. cactorum isolates from all over the world (Eikemo et al., 2004). Zoospore suspensions of $P$. cactorum were prepared as described previously (Eikemo et al., 2000). Plants were gently wounded in the rhizome with a scalpel and inoculated with $2 \mathrm{~mL}$ of the zoospore suspension $\left(1 \times 10^{5}\right.$ spores $/ \mathrm{mL}$ ) added onto the crown and lower parts of the plant with a pipette. This method of inoculation was chosen because previous experience has shown that inoculation of plug plants without wounding can lead to poor disease development (Eikemo et al., 2000). The plants were watered 1 to $2 \mathrm{~h}$ before inoculation to ensure that the soil was wet and postinoculation watered only on the pot trays, not directly onto the soil.

Disease was scored on a scale from 1 to 8 (Eikemo et al., 2000; Simpson et al., 1994). The plants that died during the first, second, third, or fourth week after inoculation were given the scores $8,7,6$, or 5 , respectively. After 4 weeks, the remaining plants were bisected longitudinally and scored 1 to 4 based on the degree of necrosis in the crown: 1 = no symptoms, 2 = a few brown/dark speckles, $3=$ small patches of necrosis, and $4=$ more than $50 \%$ of the crown necrotic.

Experimental setup and statistical analysis. Four similar experiments were conducted, each with a varying number of accessions being tested. In the first experiment, 31 genotypes were tested, and in the second, 29 additional genotypes as well as six of the extremes (susceptible and resistant) from the first experiments. In Expts. 3 and 4, 24 and four of the extreme genotypes, respectively, were tested again. Each experiment consisted of three replicates, each replicate with 12 to 15 plants, and all experiments were organized in a completely randomized block design. Control plants (wounded and inoculated with water) were included in all experiments. To get within-experiment means, the data from each experiment were analyzed using analysis of variance in which the replicates were considered random and the accessions fixed. When all the experiments were analyzed together, the effect of experiment was also considered random. The statistical model used for the overall analysis was

$$
\begin{aligned}
y_{i j k l}= & \mu+\exp _{i}+\operatorname{rep}_{j}\left(\exp _{\mathrm{i}}\right) \\
& +\operatorname{Gen}_{\mathrm{k}}+(\operatorname{Gen} \times \exp )_{\mathrm{ik}}+\mathrm{e}_{\mathrm{ijkl}}
\end{aligned}
$$

where $\mathrm{y}_{\mathrm{ijkl}}$ is the disease score on a single plant; $\mu$ is the grand mean;

exp is the random effect of experiment $i$; $\mathrm{i}=1$ to 4 ;

rep is the random effect of replicate; $j=1$ to 3 ;

Gen is the fixed or random effect of accession $\mathrm{k} ; \mathrm{k}=1$ to 60 ; and

$\mathrm{e}$ is the error on the $1^{\text {th }}$ plant; $1=1$ to 12 (or $15)$.

Disease score least square means were estimated from the mixed effects model in which the accessions were considered fixed and the experiments and replications were considered random. For the estimation of the variance components, a completely random effects model was used. The significance of the random effects was tested using the likelihood ratio (Self and Liang, 1987). Finally, the covariate (i.e., plant size) was included. All computations were done using Proc Mixed $\AA$ in SAS ${ }^{\circ}($ SAS, 1999).

\section{Results and Discussion}

There are only a few reports on resistance to $P$. cactorum in wild strawberry species. Harrison et al. (1998) tested wild octoploid strawberry ( $F$. virginiana and $F$. chiloensis) for resistance to crown rot, and Parikka (1998) included some wild diploid Fragaria genotypes among a wide selection of cultivated strawberry ( $F$. ×ananassa) cultivars. Results from both these studies indicated that there is variation in resistance to $P$. cactorum among wild strawberries and, consequently, it should be possible to find genotypes with extreme qualities in a larger collection of accessions. The results from the present study show that diploid Fragaria species vary significantly $(P<0.0001)$ in their expression of $P$. cactorum resistance. The most resistant genotypes had an average score of 1.06 (only a few plants showing symptoms after 4 weeks) and the most susceptible a score of 7.43 (all plants dead within 2 weeks). None of the control plants showed symptoms of crown rot in any of the experiments. The combined statistical analysis showed that the variance component resulting from different experiments was not significant and neither was the effect of replication within experiments. However, the accessions responded somewhat differently to the pathogen in the different experiments resulting in a different grade or rank of the cultivars between experiments, revealed as significant a genotype $x$ experiment interaction $(P<0.0001)$. The effect of plant size on disease score was not significant and hence not included in the analysis. The accession means from each experiment and the overall least square means and their corresponding SES are given in Table 1 .

Figure 1 shows the distribution of the least square means of the tested accessions across the four experiments. From this distribution, we cannot postulate anything concerning the nature of the Phytophthora resistance.
Despite the seemingly continuous distribution, the possibility of major genes being involved cannot be excluded because the noise in our data is large both the unexplained residual variance and the variance from the accession $\times$ experiment interaction. Using the $F$. vesca subset of our data in a variance component analysis, $57.6 \%$ of the total variance was attributable to differences between accessions, whereas $13.8 \%$ was the result of the accession $\times$ experiment interaction. Hence, a majority of the observed variation was genetically regulated. In an exploratory experiment like the present one, however, it is not possible to suggest any genetic mechanism for this regulation.

We are unable to postulate any differences between the most resistant accession CFRA1363, with an average score of 1.06 , and the accession CFRA1856, which has an average of 3.09. The difference between CFRA1363 and CFRA1866 with disease score 3.49 is, however, significant $(P=$ 0.0367 ), indicating that accessions with disease scores 3.49 and higher belong to a different group as far as susceptibility concerns. On the susceptible side of the distribution, we could not find any significant differences among the five most susceptible genotypesCFRA175, Haugastøl 3, CFRA1218, FDP821, and CFRA424-leaving them as a putative distinct group. In conclusion, a majority of the accessions (48) were categorized as being resistant or moderately resistant to Phytophthora cactorum. The disease score for this group varied from 1.06 to 3.09 . Five accessions with disease scores ranging from 6.25 to 7.43 were considered highly susceptible. A majority of the accessions (48) were categorized as being resistant or moderately resistant to Phytophthora cactorum. The disease score for this group varied from 1.06 to 3.09. Five accessions with disease scores ranging from 6.25 to 7.43 were considered highly susceptible.

There was no indication of any Fragaria species being more resistant or susceptible than others and no systematic differences resulting from geographic origin. The majority of accessions (48 of 60) tested were $F$. vesca, and among these, the disease scores varied from 1.06 to 7.43 . A maximum of three accessions was tested from the other Fragaria species; hence, no conclusion could be made about the general resistance level in these species. In general, the distribution of resistance to P. cactorum in diploid Fragaria is comparable to results found in $F$. $\times$ ananassa, in which the disease score ranged from 1.15 to 6.44 using the same method of disease scoring but a slightly different method of inoculation (Eikemo et al., 2003). The present results also showed that wild $F$. vesca accessions collected from the same location may have very different levels of resistance. The three Norwegian accessions named Haugastøl 1, 2, and 3 were collected in the same area within only 2 - to $3-\mathrm{km}$ distance. Two of the accessions were quite resistant (1.46 and 1.56), whereas the third, Haugastøl 3 , was very susceptible (6.65). All three 


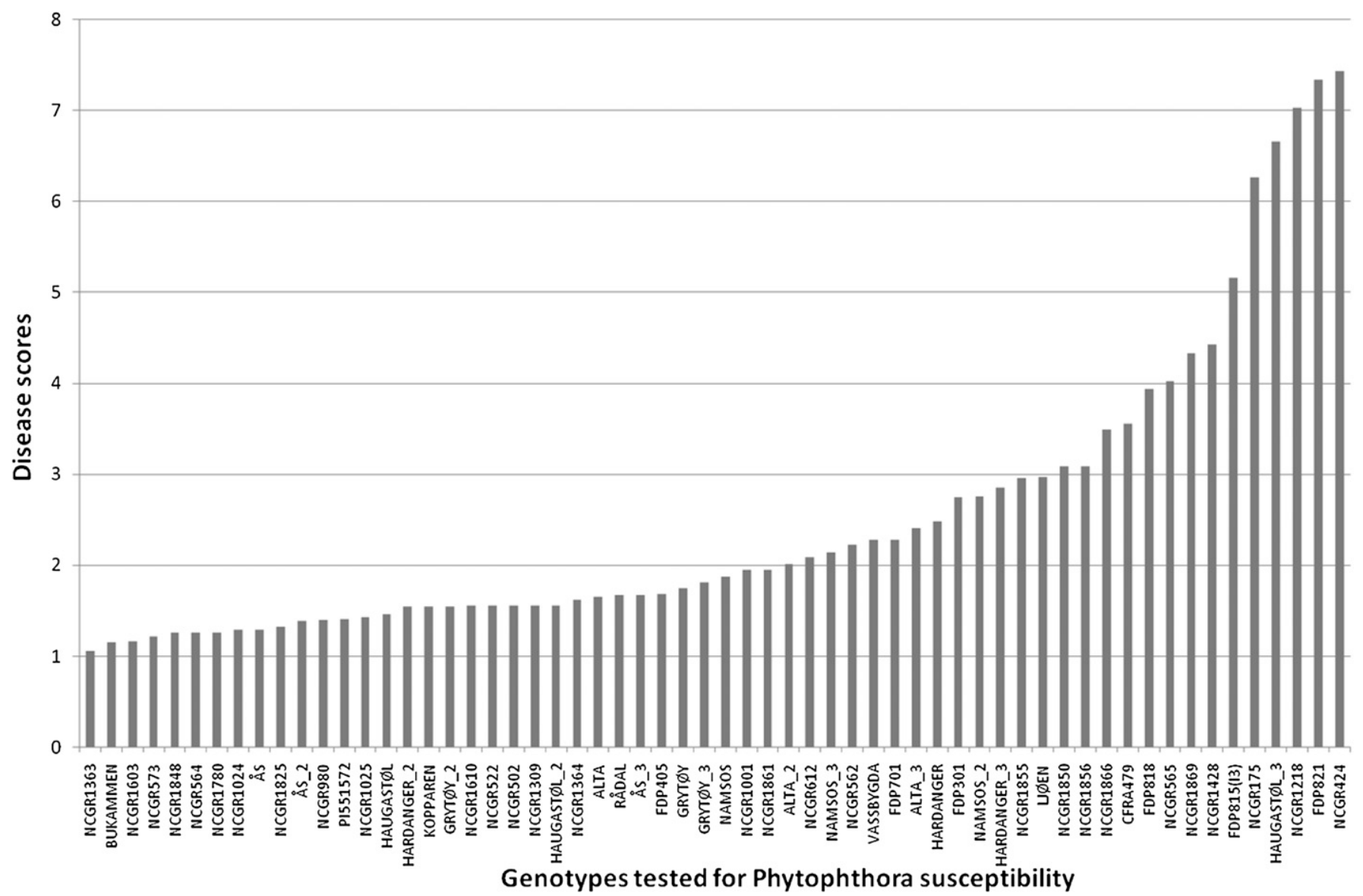

Fig. 1. The distribution of disease scores in diploid Fragaria ssp. artificially infected with zoospores from Phytophthora cactorum strain 10300. Disease was scored on a scale from 5 to 8 during 4 weeks based on when the plants died or 1 to 4 based on degree of necrosis in the rhizome of the surviving plants 4 weeks after inoculation. The accessions were obtained from National Clonal Germplasm Repository, OR (CFRA), East Malling Research, U.K. (FDP), or collected in the wild in Norway.

Haugastøl accessions were tested in two or three experiments. Our own unpublished microsatellite analysis has confirmed the divergence of Haugastøl 3 compared with the other two Haugastøl accessions. One explanation for these differences is that different accessions have been imported by humans and subsequently naturalized. Hence, the three Haugastøl accessions may have quite different origins. Multiple collections within the other sites (mainly from the Norwegian collection) showed more similar degrees of resistance.

In conclusion, we report here the results from testing of diploid Fragaria accessions for resistance to Phytophthora cactorum in a greenhouse. Both resistant and susceptible accessions have been identified. This information is necessary for gaining basic knowledge about the $P$. cactorum resistance mechanism in the $F$. vesca model system and for the identification for resistance genes and genetic markers to such genes. It is believed that such knowledge eventually will lead to the advancement in the development of $F$. Xananassa cultivars. Moreover, recent research has confirmed that there is a high degree of similarity between more distantly related genera of the Rosaceae family (Shulaev et al., 2008; Vilanova et al., 2008). This indicates that information from the $F$. vesca model system is also relevant to other economically important crops like apple or pear.

\section{Literature Cited}

Cipriani, G., F. Pinosa, M. Bonoli, and W. Faedi. 2006. A new set of microsatellite markers for Fragaria species and their application in linkage analysis. J. Hort. Sci. Biotechnol. 81:668675.

Davis, T.M. and H. Yu. 1997. A linkage map of the diploid strawberry, Fragaria vesca. J. Hered. 88:215-221.

Denoyes-Rothan, B., E. Lerceteau-Köhler, G Guérin, S. Bosseur, J. Bariac, E. Martin, and P. Roudeillac. 2004. QTL analysis for resistances to Colletotrichum acutatum and Phytophthora cactorum in octoploid strawberry (Fragaria $\times a n a n a s s a)$. Acta Hort. 663:147-151.

Deutschmann, V.F. 1954. Eine Wurzelfäule an Erdbeeren hervorgerufen durch Phytophthora cactorum (Leb. et Cohn) Schroet. Nachrichtenblatt des Deutschen Pflanzenschutzdienst, Stuttgart 6:7-9.

Eikemo, H. 1998. Crown rot in strawberries; screening methods, susceptibility of varieties. Master thesis, Agricultural University of Norway, Aas.

Eikemo, H., S.S. Klemsdal, I. Riisberg, P. Bonants, A. Stensvand, and A.A. Tronsmo. 2004. Genetic variation between Phytophthora cactorum isolates differing in their ability to cause crown rot in strawberry. Mycol. Res. 108:317-324.

Eikemo, H., A. Stensvand, J. Davik, and A.M Tronsmo. 2003. Resistance to crown rot (Phy- tophthora cactorum) in strawberry cultivars and in offspring from crosses between cultivars differing in susceptibility to the disease. Ann. Appl. Biol. 142:83-89.

Eikemo, H., A. Stensvand, and A.M. Tronsmo. 2000. Evaluation of methods of screening strawberry cultivars for resistance to crown rot caused by Phytophthora cactorum. Ann. Appl. Biol. 137:237-244.

Erwin, D.C. and O.K. Ribeiro. 1996. Phytophthora diseases worldwide. APS Press, St. Paul, MN.

Fennimore, S.A., J.M. Duniway, G.T. Browne, F.N. Martin, H.A. Ajwa, B.B. Westerdahl, R.E. Goodhue, M. Haar, and C. Winterbottom. 2008. Methyl bromide alternatives evaluated. California Agriculture 62:62-67. Mar. 2009. <http:// www.escholarship.org/uc/item/8r43j239>.

Folta, K.M. and T.M. Davis. 2006. Strawberry genes and genomics. Crit. Rev. Plant Sci. 25:399-415.

Hancock, J.F., J.J. Luby, A. Dale, P.W. Callow, S. Serce, and A. El-Shiek. 2002. Utilizing wild Fragaria virginiana in strawberry cultivar development: Inheritance of photoperiod sensitivity, fruit size, gender, female fertility and disease resistance. Euphytica 126:177184.

Harrison, R.E., J.J. Luby, G.R. Furnier, J.F. Hancock, and D. Cooley. 1998. Variation for susceptibility to crown rot and powdery mildew in wild strawberry from North America. Acta Hort. 484:43-48.

Lerceteau-Köhler, E., G. Guérin, F. Laigret, and B. Denoyes-Rothan. 2003. Characterization of 
mixed disomic and polysomic inheritance in the octoploid strawberry (Fragaria $\times$ ananassa) using AFLP mapping. Theor. Appl. Genet. 107:619-628.

Maas, J.L. 1998. Compendium of strawberry diseases. Compendium of strawberry diseases APS Press, St. Paul, MN.

Nienhaus, F. 1960. Das Wirtsspektrum von Phytophthora cactorum (Leb. et Cohn) Schroet. Phytopathol. Z. 38:33-68.

Oosumi, T., H.A. Gruszewski, L.A. Blischak, A.J. Baxter, P.A. Wadl, J.L. Shuman, R.E. Veilleux, and V. Shulev. 2006. High-efficiency transformation of the diploid strawberry (Fragaria vesca) for functional genomics. Planta 223 : 1219-1230.

Parikka, P. 1998. Testing of resistance of strawberry cultivars to crown rot [in Finnish]. Puutarha \& Kauppa 7:4-5

Pattison, J.A., S.K. Samuelian, and C.A. Weber. 2007. Inheritance of Phytophthora root rot resistance in red raspberry determined by generation means and molecular linkage analysis. Theor. Appl. Genet. 115:225-236.

Potter, D., J.J. Luby, and R.E. Harrison. 2000. Phylogenetic relationships among species of Fragaria (Rosaceae) inferred from non-coding nuclear and chloroplast DNA sequences. Syst. Bot. 25:337-348.

Rousseau-Gueutin, M., E. Lerceteau-Köhler, L. Barrot, D.J. Sargent, A. Monfort, D. Simpson, P. Arús, G. Guérin, and B. Denoyes-Rothan. 2008. Comparative genetic mapping between octoploid and diploid Fragaria species reveals a high level of colinearity between their genomes and the essentially disomic behavior of the cultivated octoploid strawberry. Genetics 179:2045-2060.

Sargent, D.J., J. Clarke, D.W. Simpson, K.R. Tobutt, P. Arús, A. Monfort, S. Vilanova, B. Denoyes-Rothan, M. Rousseau, K. Folta, N.V. Bassil, and N.H. Battey. 2006. An enhanced microsatellite map of diploid Fragaria. Theor. Appl. Genet. 112:1349-1359.

Sargent, D.J., T.M. Davis, K.R. Tobutt, M.J. Wilkinson, N.H. Battey, and D.W. Simpson. 2004. A genetic linkage map of microsatellite, gene-specific and morphological markers in diploid Fragaria. Theor. Appl. Genet. 109: 1385-1391.

SAS. 1999. SAS/STAT user's guide. Version 8. SAS Institute Inc., Cary, NC.

Self, S.G. and K.-Y. Liang. 1987. Asymptotic properties of maximum likelihood estimators and likelihood ratio tests under nonstandard conditions. Journal of the American Statistical Society 82:605-610.

Shaw, D.V., J. Hansen, and G.T. Browne. 2006 Genotypic variation for resistance to Phytophthora cactorum in a California strawberry breeding population. J. Amer. Soc. Hort. Sci. 131:687-690.

Shaw, D.V., J. Hansen, G.T. Browne, and S.M. Shaw. 2008. Components of genetic variation for resistance of strawberry to Phytophthora cactorum estimated using segregating seedling populations and their parent genotypes. Plant Pathol. 57:210-215.
Shulaev, V., S.S. Korban, B. Sosinski, A.G. Abbott, H.S. Aldwinckle, K.M. Folta, A. Iezzoni, D. Main, P. Arús, A.M. Dandekar, K. Lewers, S.K Brown, T.M. Davis, S.E. Gardiner, D. Potter, and R.E. Veilleux. 2008. Multiple models for Rosaceae genomics. Plant Physiol. 147:9851003.

Simpson, D.W., J.A. Bell, and D.C. Harris. 1994. Breeding for resistance to fungal diseases in strawberry, p. 63-66. In: Schmidt, H. and M. Kellerhals (eds.). Progress in temperate fruit breeding. Kluwer Academic Publishers, Dordrecht, The Netherlands.

Sneh, B. and D.L. McIntosh. 1974. Studies on the behaviour of Phytophthora cactorum in soil. Can. J. Bot. 52:795-802.

van de Weg, W.E. 1997. Resistance to Phytophtora fragariae var. fragariae in strawberry: The Rpf2 gene. Theor. Appl. Genet. 94:10921096.

Vilanova, S., D.J. Sargent, P. Arús, and A. Monfort. 2008. Synteny conservation between two distantly-related Rosaceae genomes: Prunus (the stone fruits) and Fragaria (the strawberry). BMC Plant Biol. 8:67.

Weebadde, C.K., D. Wang, C.E. Finn, K.S. Lewers, J.J. Luby, J. Bushakra, T.M. Sjulin, and J.F. Hancock. 2008. Using a linkage mapping approach to identify QTL for day-neutrality in the octoploid strawberry. Plant Breed. 127:94 101.

Wilhelm, S. and A.O. Paulus. 1980. How soil fumigation benefits the California strawberry industry. Plant Dis. 64:264-270. 